\title{
The Impact of Attitude Strength on the Acceptance of Green Services
}

Citation for published version (APA):

Bloemer, J. M. M., \& de Ruyter, J. C. (2002). The Impact of Attitude Strength on the Acceptance of Green Services. Journal of Retailing and Consumer Services, 9, 45-52. https://doi.org/10.1016/S09696989(01)00005-4

Document status and date:

Published: 01/01/2002

DOI:

10.1016/S0969-6989(01)00005-4

Document Version:

Publisher's PDF, also known as Version of record

\section{Please check the document version of this publication:}

- A submitted manuscript is the version of the article upon submission and before peer-review. There can be important differences between the submitted version and the official published version of record.

People interested in the research are advised to contact the author for the final version of the publication, or visit the DOI to the publisher's website.

- The final author version and the galley proof are versions of the publication after peer review.

- The final published version features the final layout of the paper including the volume, issue and page numbers.

Link to publication

\footnotetext{
General rights rights.

- You may freely distribute the URL identifying the publication in the public portal. please follow below link for the End User Agreement:

www.umlib.nl/taverne-license

Take down policy

If you believe that this document breaches copyright please contact us at:

repository@maastrichtuniversity.nl

providing details and we will investigate your claim.
}

Copyright and moral rights for the publications made accessible in the public portal are retained by the authors and/or other copyright owners and it is a condition of accessing publications that users recognise and abide by the legal requirements associated with these

- Users may download and print one copy of any publication from the public portal for the purpose of private study or research.

- You may not further distribute the material or use it for any profit-making activity or commercial gain

If the publication is distributed under the terms of Article $25 \mathrm{fa}$ of the Dutch Copyright Act, indicated by the "Taverne" license above, 


\title{
The impact of attitude strength on the acceptance of green services
}

\author{
Josée Bloemer ${ }^{\mathrm{a}, *}$, Ko de Ruyter ${ }^{\mathrm{b}}$ \\ ${ }^{a}$ Department of Applied Economics, Limburg University Centre, Universitaire Campus, B-3590 Diepenbeek, Belgium \\ ${ }^{\mathrm{b}}$ Faculty of Economics and Business Administration, Maastricht University, P.O. Box 616, 6200 MD Maastricht, The Netherlands
}

\begin{abstract}
This article focuses on the impact of attitude strength on the acceptance of a green service, the acceptance of green family insurances. Two dimensions of attitude strength are distinguished: embeddedness and commitment. Cognitive elaboration, information seeking and selective judgement are introduced as mediators. It is shown that embeddedness has a positive impact on cognitive elaboration whereas commitment has a positive effect on information seeking. Furthermore, cognitive elaboration has a positive impact on information seeking and both cognitive elaboration and information seeking have a positive effect on the selective judgement. This selective judgement clearly positively influences domain specific intended behavior or the acceptance of the green family insurance. (C) 2001 Elsevier Science Ltd. All rights reserved.
\end{abstract}

Keywords: Attitude strength; Embeddedness; Commitment; Selective judgement

\section{Introduction}

Today's economy is faced with a list of environmental problems, varying from global warming and acid rain to extinction of plant and animal species. In public policy programs and campaigns these issues have been brought to the forefront of attention. However, it has become clear that government programs have their limits imposed by budgets and effectiveness. Therefore, an increasing number of consumers are asking themselves "what can I do for the environment?" instead of "what can the government do?" (Peattie, 1995). This trend towards increased personal responsibility for environmental issues is building a more favorable attitude towards green products and retail formulas. However, less is known about the attitude towards green services. Yet, services have a direct and indirect impact on the environment. For instance, the financial services industry has slowly moved green issues to the center of its attention, no doubt as a result of its dominating role in third world debt creation and the financing of environmentally damaging projects.

If service providers are to be successful in adapting their services to their green target markets, an in-depth understanding of the antecedents of adoption seems

\footnotetext{
${ }^{*}$ Corresponding author. Tel.: + 32-11-268637; fax: + 32-11-268700.

E-mail addresses: jose.bloemer@1uc.ac.be (J. Bloemer), deruyter@mw.unimaas.nl (K. de Ruyter).
}

essential. The questions that remain unanswered are: which consumers are acting on their environmental concern? Are consumers willing to adopt a green lifestyle? and are they willing to pay a premium for green services to help achieving environmental goals? What differentiates them from those consumers that are indifferent or apathetic about environmentally friendly services? We posit that the strength of an environmental attitude will influence intended use of green services. However, from previous studies hardly an equivocally consistent pattern between attitude and behavior emerges (Pomerantz et al., 1995). This may be caused by a lack of a consistent conceptualization of the attitude strength construct as in for instance the Fishbein and Ajzen attitude theory (1975). Another plausible reason could be the lack of detail in the attitudinal measures used. In this paper one objective is to introduce and empirically demonstrate a comprehensive conceptualization of the concept of attitude strength. Additionally, we include a number of consequences of attitude strength in order to specify its relation to domain specific intended behavior. It is our premise that cognitive elaboration, information seeking and selective judgement intervene in the relationship between attitude strength and behavioral intentions.

The paper is structured as follows. First, a review is given of attitude strength related literature to develop the construct of attitude strength. Next, the behavioral implications of attitude strength will be introduced. On 
the basis of this, a conceptual model of the influence of attitude strength on the adoption of green services will be developed, resulting in several research hypotheses. After presenting the results of an empirical study aimed at testing the conceptual model, the paper will conclude with several theoretical and managerial implications of the study.

\section{Conceptualizing attitude strength}

The construct of attitude strength has received ample attention in the social psychology literature (Pomerantz et al., 1995). It has generally been acknowledged that certain attitudes are firmly and consequentially held and that others are more easily subject to change. Numerous characterizations of strong attitudes exist, such as that they are consistent over time, that they exert a strong influence on information processing and that they determine behavioral intentions and actual behavior. Likewise, substantial variability exists in both the conceptualizations and operationalizations of strength, which has lead to an extensive array of attitude attributes which have been demonstrated to be consequential for behavior (Krosnick et al., 1993; Chaiken et al., 1995). For instance, investigators have identified attitude importance as a form of strength and shown that this is associated with greater selective perception of information (Krosnick, 1988, 1990), resistance to social influence (Borgida and Howard-Pitney, 1983) and actual behavior (Jaccard and Becker, 1985). Similarly, other aspects of attitude strength such as certainty (Marks and Kamins, 1988), extremity (Petersen and Dutton, 1975), intensity (Schuman and Presser, 1981) and affectivecognitive consistency (Chaiken et al., 1995) have been related to one or more of aforementioned consequences. Recently an attempt has been made to identify general dimensions of attitude strength and to investigate differences in the effect of attitude strength dimensions. On the basis of major attitude attributes that have been used in previous research, Pomerantz et al. (1995) identify two general (higher order) dimensions of attitude strength on the basis of exploratory factor analysis applied to two data sets. One factor was labeled 'embeddedness' and it reflects the degree to which an individual feels personally attached and involved with an issue as well as the belief that one's attitude position reflects an inner self-value. The second factor 'commitment' pertains to the degree to which an individual feels secure and positive about the correctness of his or her opinion and takes a strong position in defending that belief (Pomerantz et al., 1995). Alternatively phrased, commitment is related to the certainty and extremity of the attitude position towards an issue, whereas embeddedness covers attitude dimensions of personal importance, ego involvement, and knowledge- ability. These underlying dimensions of attitude strength reported by Pomerantz et al. (1995) are in line with the findings of Abelson (1988).

The five dimensions of attitude strength (certainty, extremity, personal importance, ego involvement, and knowledgeability) have, both in combination or isolation been used in other studies that focused on the concept of attitude strength. The dimensions underlying commitment (certainty and extremity) are well established within the psychological literature. Certainty, defined as "the degree to which an individual is confident that his or her attitude toward an object is correct" (Krosnick et al., 1993, p. 1132), has been investigated in various studies (e.g., Marks and Kamins, 1988; Sample and Warland, 1973). Extremity or the degree one's "attitude deviates from the midpoint of favorable and unfavorable toward an issue" (Krosnick et al., 1993, p. 1132), also has been used frequently to define attitude strength (e.g., Ewing, 1942; Fazio and Zanna, 1978 a, b; Osgood and Tannenbaum, 1955; Peterson and Dutton, 1975). Importance, defined as "the extent to which an individual cares deeply about and is personally invested in an attitude" (Krosnick et al., 1993, p. 1133), has been the focus in several studies (e.g., Borgida and Howard-Pitney, 1983; Jaccard and Becker, 1985; Krosnick, 1988, 1990). Ego involvement measures the centrality of one's attitude towards one's self concept and value systems (Pomerantz et al., 1995 ) and has been investigated in various studies (e.g., Ostrom and Brock, 1968; Sherif et al., 1973; Spiro and Sherif, 1975). Finally, Krosnick et al. (1993, p. 1133) refer to knowledgeability as "the amount of information about an object that accompanies one's attitude toward it in memory". This dimension has been investigated by researchers such as Wood (1982), Wood and Kallgren (1988), and Wood et al. (1985). Part of the reason why attitude strength is generally considered as a fundamental construct is its impact on judgement formation and subsequent (intended) behavior. In the next section we will focus on a number of cognitive and behavioral consequences of attitude strength.

\section{Consequences of attitude strength}

Despite the variation in conceptualizations of attitude strength a unifying theme with respect to the construct is that strong attitudes are consequential (Pomerantz et al., 1995). It seems, therefore, particularly relevant to examine the consequences of attitude strength. As Pomerantz et al. (1995) argue, this is especially true for the processing of domain-relevant information (i.e., in our case green services). In fact, attitude strength has been defined pragmatically as those attitudes that lead to selective cognitive processing and intended and actual behavior. So far, however, it has remained unclear what 
the exact relationship is between the two components of attitude strength (commitment and embeddedness) and their consequences in terms of domain-specific intended behavior.

Before we focus on this relationship we need to introduce a number of consequences of attitude strength. First of all, it has been demonstrated that attitude strength leads to cognitive elaboration (Chaiken et al., 1995). In the same context Pomerantz et al, (1995) demonstrate that commitment is positively related to cognitive elaboration whereas embeddedness is negatively related to cognitive elaboration. In the case of green services, consumers that take a strong stand on environmental issues are more likely to stop and think about these issues. It refers to the fact of whether an individual is interested in information about the attitude object and willing to process that information. In turn, cognitive elaboration on a particular domain may instigate an individual to engage in active information seeking behavior. In our case, consumers would actively search for additional information concerning green services. In addition, Pomerantz et al. (1995) show that embeddedness is associated with more information seeking whereas commitment was unrelated to this variable. Finally, it has been argued and demonstrated by Pomenrantz et al. (1995) that cognitive elaboration leads to the formation of a selective judgement (i.e., a specific opinion on a particular green service). This being in line with the so-called mere thought effect as for instance demonstrated by Tesser and Leone (1977). Research has also shown that the mere thought effect is more likely when consumers are committed to their attitudes (Tesser and Leone, 1977).

The concept of selective judgement has been identified as a central mechanism for translating general attitude strength into domain-specific intended and actual behavior (Eagly and Chaiken, 1993). Lord et al. (1979) argue that selective judgement, as a result of (selective) cognitive elaboration leads attitudes to preserve and result in behavior (adoption of the green service), despite the occurrence of non-congruent information. Nevertheless, there still is a lack of systematic research examining the relation between multiple aspects of attitude strength, cognitive elaboration, information seeking, selective judgement and domain specific intended behavior. Next, we will develop a set of hypotheses on the relationship between commitment and embeddedness as the two attitude strength dimensions and the aforementioned consequences.

\section{Development of hypotheses}

In line with Pomerantz et al. (1995), we expect that commitment has a positive impact on cognitive elaboration whereas embeddedness has a negative impact on cognitive elaboration. Also in line with Pomerantz et al. (1995), we propose a positive relationship between embeddedness and information seeking and no relationship between commitment and information seeking. Moreover, we expect a positive relationship between cognitive elaboration and selective judgement. Based on Eagly and Chaiken (1993), we hypothesize that the relationship between selective judgement and domain specific intended behavior will be positive.

Furthermore, we expect a positive influence of cognitive elaboration on information seeking. Capon and Davis (1984) show a positive relationship between the level of cognitive elaboration of consumers and information seeking. Those consumers who process information in a more complex way also acquire more information. Furthermore, also in line with the aforementioned mere thought effect it has been demonstrated that information that is inconsistent with the initial opinion tends to be overlooked, discounted, or perhaps even distorted (Tesser, 1978). This means that it could be expected that consumers when they look for additional information search for information, which is in line with their initial attitude. (Compare also Lord et al., 1979.) We therefore, expect information seeking to have a positive influence on the selective judgement.

Summing up, we propose cognitive elaboration and information seeking to be mediating variables between the two dimensions of attitude strength (commitment and embeddedness) and selective judgement. Moreover, we propose selective judgement to be a mediating variable between cognitive elaboration and information seeking on the one hand and domain specific intended behavior on the other hand.

The following hypotheses can be formulated:

\section{$\mathrm{H1}$ : Commitment has a positive effect on cognitive} elaboration.

H2: Commitment has no effect on information seeking.

$\mathrm{H} 3$ : Embeddedness has a negative effect on cognitive elaboration.

H4: Embeddedness has a positive effect on information seeking.

H5: Cognitive elaboration has a positive effect on information seeking.

H6: Cognitive elaboration has a positive effect on the selective judgement towards an object or issue.

$\mathrm{H} 7$ : Information seeking has a positive effect on the selective judgement towards an object or issue.

H8: The selective judgement towards an object of issue has a positive effect on the domain specific intended behavior.

These hypotheses are summarized in our conceptual model, which is depicted as Fig. 1. 


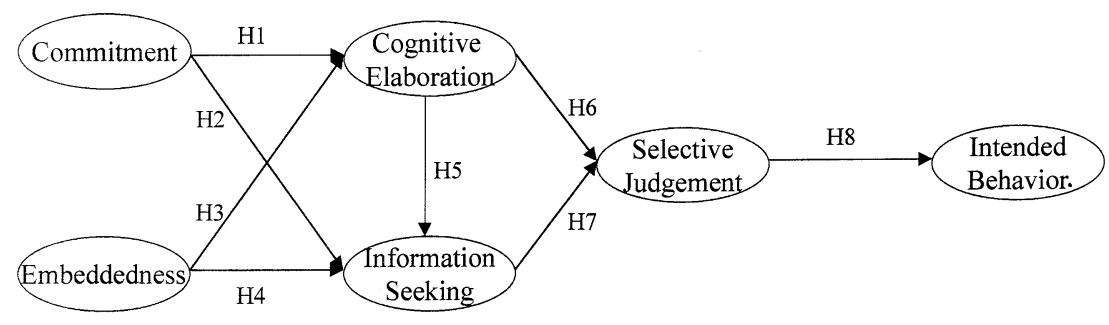

Fig. 1. Conceptual model.

\section{Empirical research}

\subsection{Research setting}

In our empirical research we focused on the green offering of a financial services provider. In particular, our study was directed at measuring consumers' attitudes towards green insurance policies, which form a recent service innovation offered by multiple insurance companies in various European markets. A green insurance policy involves a regular family insurance from which part of the fee is transferred by the insurance company to the World's Nature Foundation. This foundation uses the money for preserving the environment. The 'green' insurance covers the same expenses as a regular insurance, nevertheless it costs $5 \%$ more.

\subsection{Data collection}

Data were gathered by means of personal interviews with customers in a mid-sized city in the Flemish speaking part of Belgium. Interviewers were instructed to select respondents on a random basis in the main shopping district during shopping hours. First of all, 225 respondents were asked whether they had a family insurance. If they had, they were asked to take part in our research and to answer about 30 questions on the green insurance service. This procedure resulted in 150 completely filled out and usable questionnaires. Respondents were asked questions with regard to attitude strength towards green services in general, cognitive elaboration and information seeking on that topic, their selective judgement towards it and their intended behavior towards a green insurance policy.

\subsection{Questionnaire development}

The following multiple item constructs were employed in the survey. Attitude strength was measured with a 14 item 9-points Likert scale. In line with Pomerantz et al. (1995) the scale included 4 dimensions of attitude strength: certainty (extremity), personal involvement, ego involvement and knowledge. Certainty was assessed with statements like "It is not very likely that I change my opinions about environmental issues" and "I am very sure that my opinions about environmental issues are right". To assess personal importance, participants had to express their opinion on statements like: "Environmental issues are very important to me personally" and "Environmental issues are an important issue in society". Ego involvement was measured with items like: "I see myself as a person who is involved with environmental issues" and "Environmental preservation is one of the things that I think are important in life". Finally, knowledge was measured with items like: "I have a lot of knowledge about environmental affairs" and "I am well aware of those issues that relate to environmental preservation".

Cognitive elaboration was operationalized with a 4 item, 9-points Likert scale. Items like "I give thought to suggestions about environmental issues" and "I elaborate upon knowledge about environmental issues".

Info seeking was each measured with a 4 item, 9points Likert scale. Here we used items like: "I actively seek information on environmental issues" and "I try to add new knowledge about environment issues to my existing knowledge".

The strength of the selective judgment was measured with a 6 item, 9-points Likert scale which included items like: "I am willing to write a letter to some representative or government official about my opinion about environmental issues"; "I would join an organization that supported my position on environmental affairs" and "I engage in a debate with someone about my position on environmental affairs".

Intended behavior toward a green insurance was measures with a 3 item, 9-points behavioral intention scale based on Parasuraman (1995). Questions were formulated as follows: "I am very willing to consider a green insurance as my first choice"; "I am very willing to switch to a green insurance" and "I definitely would like to try a green insurance".

\section{Results}

\subsection{Construct validation}

Before testing the hypothesized relationships in the conceptual model, the scales used to operationalize the 
constructs were examined through estimation of the measurement model (Anderson and Gerbing, 1988; Netemeyer et al., 1990). Confirmatory factor analyses are used to assess the unidimensionality, the reliability, and validity of all constructs in our model.

As the number of items adversely affects the acceptance of structural equation models, we split the constructs used in our study into three subsets (Netemeyer et al., 1990). The first model (Model 1) includes commitment and embeddedness (14 items). The second model (Model 2) is concerned with cognitive elaboration and information seeking ( 8 items). Finally, the third model (Model 3) focuses on the strength of selective judgement and domain specific intended behavior (9 items).

\subsection{Unidimensionality}

The overall fit of the model provides the necessary and sufficient information to determine whether a set of items is unidimensional. In Model 1 we initially obtained an unacceptable fit. After inspection of the $t$ values, pattern of standardized residuals and the modification indices, we decided to delete two items for commitment and three items for embeddedness. Subsequently, we obtained a good fit: $\mathrm{GFI}=0.92$; $\mathrm{AGFI}=0.87 ; \mathrm{RMSEA}=0.084 ; \mathrm{TLI}=0.95 ; \mathrm{CFI}=0.96$.

For Model 2, we initially also obtained an unacceptable fit. Following the same procedure as described for Model 1, we deleted one item for cognitive elaboration and one item for information seeking. The resulting model showed a good fit to the data: $G F I=0.99$; AGFI $=0.99$; RMSEA $=0.001 ;$ TLI $=0.96 ;$ CFI $=0.98$. Finally, we assessed the unidimensionality of Model 3. Based on the pattern of standardized residuals we decided to eliminate one item. The respecified model has the following fit statistics: $\mathrm{GFI}=0.93 ; \mathrm{AGFI}=0.87$; RMSEA $=0.092 ;$ TLI $=0.96 ; \mathrm{CFI}=0.98$.

\subsection{Reliability}

Cronbach's alpha is used to assess the reliability of all constructs. All constructs exceed the recommended level of 0.70: commitment (0.84), embeddedness (0.88), cognitive elaboration (0.88), information seeking (0.94), selective judgment (0.84) and domain specific intended behavior (0.97).

\subsection{Convergent validity}

Within-method convergent validity was assessed testing the significance and magnitude of each indicator's coefficient (Anderson and Gerbing, 1988). We found that all items loaded higher than 0.50 on their respective constructs, all having highly significant $t$ values.

\subsection{Discriminant validity}

Discriminant validity was evaluated by testing whether pairs of constructs were correlated less than unity. We used chi-square difference tests with one degree of freedom to test for unity between the constructs. All tests were significant at the 5\% significance level. Inspection of the correlation matrix and the accompanying standard errors reveals that none of the correlations are within two standard errors of 1.0, which indicates the existence of discriminant validity. Applying Fornell and Larcker's (1981) test of average trait variance extracted, all of the constructs pairs demonstrate that the average variance extracted from the traits exceeds the squared correlation estimate between the two constructs.

\subsection{Model testing}

In order to test the hypothesized relationships in our conceptual model we used the partial aggregation model. A correlation matrix on the basis of listwise deletion of missing values was calculated using PRELIS2 and was used as an input to LISREL8. We used maximum likelihood estimation to estimate the free parameters in our conceptual model. The results of our hypothesis testing are discussed below.

Estimating the conceptual model leads to a model with a good fit. Inspection of the $t$-values pointed out that two paths were not significant. Deleting these paths did not significantly affect the fit of the model but resulted in a more parsimonious model. The following fit statistics apply: $\chi^{2}(8)=9.43(p=0.15) ; \mathrm{GFI}=0.98$; AGFI $=0.93 ;$ RMSEA $=0.062 ;$ TLI $=0.98 ;$ CFI $=0.99$. The empirical results are depicted in Fig. 2.

As can be seen from Fig. 2, commitment has a significant positive influence on information seeking (standardized path coefficient $=0.29 ; \quad t$-value $=2.46$ ) . Since this is not in line with our expectations we have to reject hypothesis 2. Moreover, cognitive elaboration is not significantly influenced by commitment, therefore we may also reject hypothesis 1 . Embeddedness, on the other hand, has a significant positive influence on cognitive elaboration (standardized path coefficient $=0.63 ; t$-value $=5.55$ ), but does not significantly influences information seeking. Therefore, we have to reject hypotheses 3 and 4 . All other relationships in the model are significant and positive and as hypothesized. Therefore, hypotheses 5, 6, 7, and 8 could be accepted. More specifically, cognitive elaboration exerts a significant positive influence on information seeking (standardized path coefficient $=0.36 ; t$-value $=3.07$ ). Selective judgement is significantly influenced by both cognitive elaboration (standardized path coefficient $=0.49 ; t$-value $=6.75$ ) and information seeking (standardized path coefficient $=0.50 ; t$-value $=7.04$ ). 


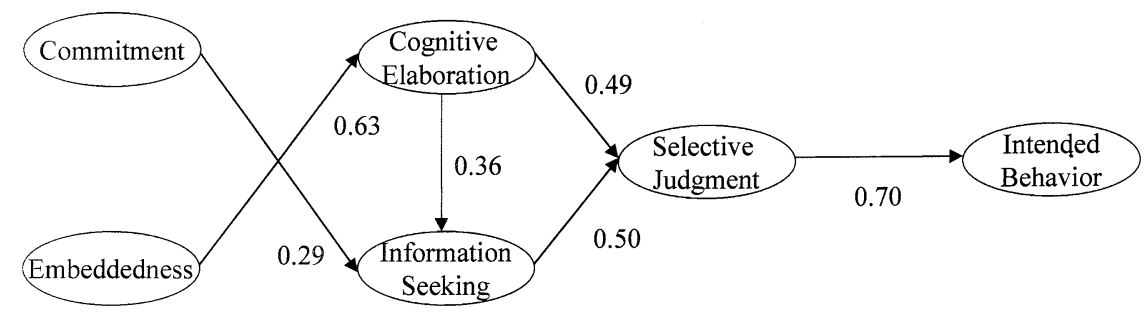

Fig. 2. Empirical model.

Furthermore, selective judgement has a significant positive influence on domain specific intended behavior (standardized path coefficient $=0.70 ; t$-value $=9.98$ ).

\section{Conclusions}

\subsection{Discussion}

Our results show that a distinction should be made between two different aspects of attitude strength: commitment and embeddedness. Both have different relationships with cognitive elaboration, information seeking, selective judgement and domain specific behavioral intentions. We demonstrate that commitment is positively related to information seeking and that emeddedness is positively related to cognitive elaboration. Furthermore, we show that both cognitive elaboration and information seeking have a positive impact on selective judgement and that selective judgement in the end has a clear positive effect on the domainspecific behavioral intentions.

Arguably, the relationships that were not encountered in the empirical study may be as interesting as the one's encountered. It is remarkable that we failed to find a positive relationship between commitment and cognitive elaboration. Neither did we find a positive relationship between embeddedness and information seeking. Moreover, the negative relationship we proposed between embeddedness and cognitive elaboration turned out to be positive. The absence of a positive relationship between commitment and cognitive elaboration might be attributed to the certainty of the attitude held. Since the consumer has no doubts about the correctness of the strong attitude, it does not seem to be important to that consumer to elaborate upon that specific attitude any longer. When this consumer nevertheless is seeking additional information, it might be expected that he or she is especially looking for congruent information and is overlooking dis-congruent information. The information that is searched for should support his of her certainty about the correctness of the attitude held and should subscribe its extremity. Commitment leads to information seeking but does not lead to cognitive elaboration.
The absence of a positive relationship between embeddedness and information seeking might be attributed to the fact that embeddedness links the attitude to the self. Embeddedness in terms of personal importance and ego involvement and even knowledge points out to the incorporation of the attitude within the existing knowledge structure of the consumer. In order to avoid cognitive dissonance strongly held attitudes need to fit within and be supported by the existing attitude structure. This might in the first place ask for cognitive elaboration. Information seeking might even disturb this process. Embeddeness leads to cognitive elaboration but does not lead to information seeking.

\subsection{Theoretical implications}

Our research should be seen as a preliminary attempt at addressing an issue that has important implications for green services marketing theory and practice. Any preliminary attempt will involve a number of limitations. However, acknowledgement of these limitations also suggests new directions for future studies. In the first place, conceptual models as well as scales for measuring attitude strength need further development and refinement. Differences in the nature of service setting might require additional dimensions of attitude strength. Further research should also incorporate multiple measures of the relevant constructs. Moreover, our study focused on domain specific intended behavior and these intentions are an incomplete proxy for actual behavior. They should be supplemented by behavioral measures in order to develop a composite index of green service loyalty. Therefore, further research should also take actual (re)actions of consumers to green services into account. An area that definitely also merits further investigation is price sensitivity, especially because green services are usually higher priced in comparison to standard service offerings. Next, the empirical relationships reported in this paper are tentative in the sense that they are based on cross-sectional data collected at one moment in time. Longitudinal research that focuses on the dynamics of the constructs over time is needed to define the exact causal nature of the link between the constructs. Furthermore, the use of multiple time frames allows for an investigation of the reinforcement effect of 
behavioral intentions on future service perceptions as well as other outcome variables that determine the strength of customer-organization relationships such as commitment, trust and customer value. Finally, for the purpose of cross-validation, additional exploration of the attitude strength-domain specific intended behavior needs to be extended beyond the settings reported here. Further conceptual and empirical research addressing aforementioned topics may yield a more in-depth insight into the nature of attitude strength and (intended) behavior.

\subsection{Managerial implications}

A starting point of this article was the issue of personal responsibility for environmental matters brings the concept of attitude strength to the forefront of marketing's attention. From a managerial perspective, increasing the strength of a favorable attitude means that attitude has a stronger influence on subsequent behavior. The results of our research clearly show the stronger the attitude towards environmental issues, the more the consumer is willing to pay attention to these issues in terms of thinking about them and searching for information about them. This positively influences the consumers' selective judgment and his or her intention to act in accordance with his or her selective judgment. More specifically, commitment as one of the dimensions of attitude strength has a positive impact on information seeking and embeddedness, as the other dimension of attitude strength has a positive effect on cognitive elaboration. This means that when one wants to direct the behavior of the consumer in a certain direction, the attitude that forms the basis of that behavior should be strengthened as much as possible. A strong attitude has a positive impact on cognitive elaboration which helps integrate the strongly held attitude with already present knowledge in order to embed the attitude in the existing knowledge structure. This will subsequently have a stronger impact on the intended behavior. A strong attitude has also an impact on the information sought by the consumer. Extra information sought should therefore be presented in accordance with the strongly held attitude so that it supports the already strong attitude and makes it even stronger. Both cognitive elaboration and information seeking in turn will have a positive influence on the selective judgment of the consumer which will be even more selective depending on the degree of cognitive elaboration and the degree of information seeking and finding congruent information. Finally, the intended behavior will be more in line with the strongly held attitude.

So, create a strong attitude. Make sure that the consumer thinks about this attitude and integrates it with already existing knowledge. Make the consumer seek for additional information and present information that is in line with and supports the attitude held. As a result, the consumer will make a selective judgment, which he or she at least intends to act upon.

In terms of a green insurance this means that the stronger the positive attitude towards environmental issues, the more the consumer is willing to think about this issues and the more information he or she is seeking on this topic. All this influences his or her selective judgment about environmental issues positively and this will be acted upon in the end. This consumer is more willing to consider a green insurance as his/her first choice; is more willing to switch to a green insurance and would more definitely like to try a green insurance.

\section{References}

Abelson, R.P., 1988. Conviction. American Psychologist 43, 267-275. Anderson, J.C., Gerbing, D.W., 1988. Structural equation modeling in practice: a review and recommended two-step approach. Psychological Bulletin 103, 411-423.

Borgida, E., Howard-Pitney, B., 1983. Personal involvement and the robustness of perceptual salience effects. Journal of Personality and Social Psychology 45, 560-570.

Capon, N., Davis, R., 1984. Basic cognitive ability measures as predictors of consumer information processing strategies. Journal of Consumer Research 11, 551-563.

Chaiken, S., Pomerantz, E.M., Giner-Sorolla, R., 1995. Structural consistencies and attitude strength. In: Petty, R.E., Krosnick, J.A. (Eds.), Attitude Strength: Antecedents and Consequences. Erlbaum, Hillsdale, NJ.

Eagly, A.H., Chaiken, S., 1993. The Psychology of Attitudes. Harcourt Brace Jovanovich College Publishers, Fort Worth, TX.

Ewing, T.M., 1942. A study of certain factors involved in changes of opinion. Journal of Social Psychology 16, 63-88.

Fazio, R.H., Zanna, M.P., 1978a. Attitudinal qualities relating to the strength of the attitude-behavior relationship. Journal of Experimental Social Psychology 14, 398-408.

Fazio, R.H., Zanna, M.P., 1978b. On the predictive validity of attitudes: the role of direct experience and confidence. Journal of Personality 46, 228-243.

Fishbein, M., Ajzen, I., 1975. Belief, attitude, intention and behavior: an introduction to theory and research. Addison-Wesley, Reading, MA.

Fornell, C., Larcker, D.F., 1981. Structural equation models with unobservable variables and measurement error: algebra and statistics. Journal of Marketing Research 18 (3), 375-382.

Jaccard, J., Becker, M.A., 1985. Attitudes and behavior: an information integration perspective. Journal of Experimental Social Psychology 21, 440-465.

Krosnick, J.A., 1988. Attitude importance and attitude change. Journal of Experimental Social Psychology 24, 240-255.

Krosnick, J.A., 1990. Americans perceptions of presidential candidates: a test of the projection hypothesis. Journal of Social Issues 46, 159-182.

Krosnick, J.A., Boninger, D.S., Chuang, Y.C., Berent, M.K., Carnot, C.G., 1993. Attitude strength: one construct or many related constructs. Journal of Personality and Social Psychology 65 (6), 1132-1151.

Lord, C.G., Ross, L., Lepper, M.R., 1979. Biased assimilation and attitude polarization: the effects of prior theories on subsequently considered evidence. Journal of Personality and Social Psychology 37, 2098-2109. 
Marks, L.J., Kamins, M.A., 1988. The use of product samples and advertising: effects of sequences of exposure and degree of advertising claims exaggeration on consumers beliefs strength, belief confidence, and attitudes. Journal of Marketing Research 25, $266-281$.

Netemeyer, R.G., Johnston, M.W., Burton, S., 1990. Analysis of role conflict and role ambiguity in a structural equations framework. Journal of Applied Psychology 75, 148-157.

Osgood, C.E., Tannenbaum, P.H., 1955. The principle of congruity in the predication of attitude change. Psychological Review 62, 40-55.

Ostrom, T.M., Brock, T.C., 1968. A cognitive model of attitudinal involvement. In: Abelson, R.P., Aronson, W.J., McGuire, Newcomb, T. M., Rosenberg, M. J., Tannenbaum, P. H. (Eds.), Theories of Cognitive Consistency: A Sourcebook. Rand McNally, Chicago, pp. 373-383.

Parasuraman, A., 1995. Measuring and Monitoring service quality. In: Glynn, W.J., Barnes, J.G. (Eds.), Understanding Services Management. Wiley, Chisester, pp. 143-177.

Peattie, K., 1995. Environmental Marketing Management. Meeting the Green Challenge. Pitman Publishing, London.

Petersen, K., Dutton, J.E., 1975. Certainty, extremity, intensity. Neglected variables in research on attitude-behavior consistency. Social Forces 54, 393-414.

Pomerantz, E.M., Chaiken, S., Tordesillas, R.S., 1995. Attitude strength and resistance processes. Journal of Personality and Social Psychology 69 (3), 408-419.

Sample, J., Warland, R., 1973. Attitudes and the prediction of behavior. Social Forces 52, 292-328.
Schuman, H., Presser, S., 1981. Questions and answers in attitude surveys: experiments on question form, wording and context. Academic Press, New York.

Sherif, C.W., Kelly, M., Rogers, H.L., Sarup, G., Tittler, B.I., 1973. Personal involvement, social judgment, and action. Journal of Personality and Social Psychology 27, 211-228.

Spiro, R.J., Sherif, C.W., 1975. Consistency and relativity in selective recall with differing ego-involvement. Journal of Social and Clinical Psychology 14, 351-361.

Tesser, A., 1978. Self-generated attitude change. In: Berkowitz, L. (Ed.), Advances in Experimental Social Psychology. Academic Press, San Diego, CA, pp. 289-338.

Tesser, A., Leone, C., 1977. Cognitive schemas and thought as determinants of attitude change. Journal of Experimental Social Psychology 13, 340-356.

Wood, W., 1982. Retrieval of attitude relevant information from memory. Effects of susceptibility to persuasion and on intrinsic motivation. Journal of Personality and Social Psychology 41, 198-810.

Wood, W., Kallgren, C.A., 1988. Communicator attributes and persuasion: recipients access to attitude-relevant informa tion in memory. Personality and Social Psychology Bulletin 14, 172-182.

Wood, W., Kallgren, C.A., Preisler, R.M., 1985. Access to attituderelevant information in memory as a determinant of persuasion: the role of message attributes. Journal of Experimental Social Psychology $21,73-85$. 